\title{
Enhanced Photocatalytic Activity of Reduced Graphene Oxide/Bismuth Sulfide Nanostructure Composites for the Degradation of Methylene Blue
}

\author{
Bayisa Meka Chufa $\mathbb{D}^{1},{ }^{1}$ Bedasa Abdisa Gonfa $\mathbb{D}^{1},{ }^{1}$ and Teketel Yohannes Anshebo $\mathbb{D}^{2}$ \\ ${ }^{1}$ Department of Applied Chemistry, School of Applied Natural Science, Adama Science and Technology University, P.O. Box 1888, \\ Adama, Ethiopia \\ ${ }^{2}$ Department of Chemistry, School of Natural Science, Addis Ababa University, P.O. Box 1176, Addis Ababa, Ethiopia
}

Correspondence should be addressed to Bayisa Meka Chufa; nathan.meka@astu.edu.et

Received 28 May 2021; Revised 25 July 2021; Accepted 18 August 2021; Published 15 September 2021

Academic Editor: Kishore Sridharan

Copyright (C) 2021 Bayisa Meka Chufa et al. This is an open access article distributed under the Creative Commons Attribution License, which permits unrestricted use, distribution, and reproduction in any medium, provided the original work is properly cited.

\begin{abstract}
Today, the issue of the environment is the concern of scientists worldwide. Aside from developed countries, developing countries are revolutionizing their economy from agriculture to industries, aggravating the discharge of pollutants. Textile industries are the main sources of pollutant dyes such as methylene blue (MB). In this study, a simple and green synthesis method was used to manufacture a nanostructure heterogeneous photocatalyst, $\mathrm{rGO}-\mathrm{Bi}_{2} \mathrm{~S}_{3}$, for the degradation of $\mathrm{MB} \mathrm{Bi}_{2} \mathrm{~S}_{3}$ and $\mathrm{rGO}$ were synthesized separately using Vernonia amygdalina (VA) plant extract. $\mathrm{rGO}-\mathrm{Bi}_{2} \mathrm{~S}_{3}$ was synthesized using a single-step refluxed hydrothermal method. The products were characterized by XRD, FT-IR, UV-Vis, DTA, TGA, and visual techniques. The comparative degradability degree of the dye under visible light irradiation with and without the presence of the catalyst was studied. The performance test results showed 99\% degradation of MB in the presence and 7\% in the absence of the catalyst under the same condition for the duration of 25 minutes. The durability and reusability tests for the catalyst were also studied for five cycles. The maximum decrease in the degradation capacity of the catalyst for the duration of 25 minutes was $0.5 \%$. Hence, $\mathrm{rGO}-\mathrm{Bi}_{2} \mathrm{~S}_{3}$ is found to be the ideal material for the degradation of $\mathrm{MB}$, for environmental protection.
\end{abstract}

\section{Introduction}

Nanosized materials are materials exhibiting unique physical, chemical, mechanical, electrical, biological, and thermal properties than their bulk counter parts due to their high surface area, small particle size, and possible quantum confinement effects [1-3]. Semiconductor materials are solid materials having an energy band gap lying in between a conductor and an insulator. Semiconductor materials manufactured to the nanoscale shares the above described nanomaterial properties. The development of these materials necessitates the progress of sciences: chemistry, physics engineering, and technology of the materials $[4,5]$. A bismuth sulfide nanostructure $\left(\mathrm{Bi}_{2} \mathrm{~S}_{3}\right)$ is a semiconductor material with unique features such as favorable energy band gap, high absorption coefficient, and environmentally friendly elemental composition than the other known semiconductor [6-8]. $\mathrm{Bi}_{2} \mathrm{~S}_{3}$ has a direct narrow band gap energy of $1.34 \mathrm{eV}$ and finds application in photodiode arrays, photovoltaic convertors, and thermoelectric cooling devices based on Peltier effects [4, 9-13].

The $21^{\text {st }}$ century is termed as the century of the environment [14]. The world population is growing at the fastest rate, and this resulted in the intensification of industrial activities which in turn resulted in the contamination of the environment. For instance, textile industries are the main sources of dyes, which are the top pollutants of water bodies [15-17], and $\mathrm{Bi}_{2} \mathrm{~S}_{3}$ has been attracting significant attention of researchers owing to its interesting band gap in the photocatalysis application for water purification [18-20]. However, the small band gap of $\mathrm{Bi}_{2} \mathrm{~S}_{3}$ is subjected to the risk of charge carrier recombination and inefficient light response range, but it is still very effective and efficient if composited with graphene- 
based nanomaterials, forming a heterojunction, which stabilizes the band gap and optimizes its light absorption range [21-23]. Heterojunctions play a great role in mitigating the aforementioned drawbacks [24-26].

Different synthesis methods of $\mathrm{Bi}_{2} \mathrm{~S}_{3}$ have been reported so far; however, many of them are chemical methods that discharge hazardous pollutants to the environment [19, 27]. Because of its nontoxicity, energy band gap, light absorption potential, and ease of fabrication, $\mathrm{Bi}_{2} \mathrm{~S}_{3}$ has been the preferred and widely used semiconductor [28-30]. Hence, the safe, cheap, and simple synthesis method of $\mathrm{Bi}_{2} \mathrm{~S}_{3}$ semiconductors should be devised by researchers.

As indicated in many recent research works, different approaches such as constructing heterostructured photocatalysts for the charge separation efficiency and extending the light response range by coupling the suitable band gap structure of materials are the most promising to promote photocatalytic efficiency of $\mathrm{Bi}_{2} \mathrm{~S}_{3}[31,32]$. Owing to their unique electronic properties for application of photovoltaic devices, graphene has attracted interest of researchers recently [31]. Graphene possesses properties such as a high specific surface area $\left(2600 \mathrm{~m}^{2} \mathrm{~g}^{-1}\right)$, electrical conductivity $\left(550 \mathrm{~S} \mathrm{~cm}^{-1}\right)$, electron mobility at room temperature $\left(200,000 \mathrm{~cm}^{2} \mathrm{v}^{-1} \mathrm{~s}^{-1}\right)$, and current density up to six orders of magnitude higher than copper [33] which are important for the application of photocatalytic activities. Therefore, the combination of the delocalized electron-rich materials like $\mathrm{rGO}$ and semiconductor $\mathrm{Bi}_{2} \mathrm{~S}_{3}$ to form the heterostructure nanocomposite $\mathrm{rGO}-\mathrm{Bi}_{2} \mathrm{~S}_{3}$ allows the stability of the band gap of the semiconductor and modifies the light harvesting capacity of the heterostructure $[34,35]$.

In this work, we presented a cheap, simple, and green synthesis method of $\mathrm{Bi}_{2} \mathrm{~S}_{3}$ using methanol extracted compounds of Vernonia amygdalina at a low temperature below $100^{\circ} \mathrm{C}$. Bitter leaf (Vernonia amygdalina, VA) is a soft wood shrub tree commonly found naturally in tropical Africa and Asia. It is a promising plant in research and development and often used as a traditional medicine and for nutritional purposes $[36,37]$. The plant extract was used as a capping agent for the stabilization of the product nanostructure. Graphene oxide (GO) was synthesized using the improved method with a slight modification, and it was reduced to produce reduced graphene oxide ( $\mathrm{rGO}$ ) by the green synthesis method. The rGO- $\mathrm{Bi}_{2} \mathrm{~S}_{3}$ composite was synthesized from the mixture of rGO and $\mathrm{Bi}_{2} \mathrm{~S}_{3}$ under a single-step refluxed hydrothermal method. This method of synthesis is a solution reaction-based approach. The hydrothermal autoclave reactor is used to carry the hydrothermal reaction at a high pressure and temperature [38]. The enhanced photocatalytic activity of $\mathrm{Bi}_{2} \mathrm{~S}_{3}$ using $\mathrm{rGO}$ for the degradation of methylene blue (MB) was studied thoroughly. The durability and reusability of the heterogeneous catalyst were also explored exhaustively.

\section{Materials and Methods}

2.1. Materials. Thiourea $\left(\mathrm{CH}_{4} \mathrm{~N}_{2} \mathrm{~S}\right)$, bismuth chloride $\left(\mathrm{BiCl}_{3}\right)$, methanol (99.8\%), ethanol (98\%), and distilled water were used directly as purchased without further treat- ment, and bitter leaf plant extract was synthesized in the lab. 100 microns of graphite powder (99.5\% purity), sulfuric acid (98\%), phosphoric acid (75\%), hydrogen peroxide (35\%), hydrochloric acid (37\%), potassium permanganate $(99.5 \%)$, barium chloride (99\%), and deionized water were also used to synthesize the catalyst as rGO [39].

2.2. Synthesis of $\mathrm{Bi}_{2} \mathrm{~S}_{3}$. $1.5 \mathrm{~g}$ of bismuth chloride $\left(\mathrm{BiCl}_{3}\right)$ and $1.2 \mathrm{~g}$ of thiourea $\left(\mathrm{CH}_{4} \mathrm{~N}_{2} \mathrm{~S}\right)$ were dissolved in $50 \mathrm{ml}$ of distilled water each and mixed while continuously stirring using a heater with magnetic stirrer at $100^{\circ} \mathrm{C}$. After 5 minutes of heating, add $10 \mathrm{ml}$ of methanol extracted compounds of Vernonia amygdalina into the solution. Then, the mixture was set on indirect heating using a water bath under continuous stirring for six hours. Then finally, the black powder was obtained after being washed using distilled water and ethanol several times and oven dried at $60^{\circ} \mathrm{C}$ for 12 hours.

2.3. Synthesis of $r G O$. The green synthesis method was used to obtain the catalyst, rGO, by using a bitter leaf plant extract as a reducing agent. The leaf extract was prepared by taking $10 \mathrm{~g}$ of the ground powder and adding into a $500 \mathrm{ml}$ borosilicate beaker. Then, 10 grams of the powder was dissolved in $100 \mathrm{ml}$ of methanol, and the mixture was heated on a heater with a magnetic stirrer to the boiling point of methanol until the complete removal of the solvent. The hot solution was taken off and cooled naturally at room temperature. And then, the extract was filtered using Whatman number 1 filter paper. The resulting filtrates were further concentrated over a water bath at $40-50^{\circ} \mathrm{C}$ for solvent removal. The stock solutions of crude extracts were prepared, and desired working concentrations were made by appropriate techniques. The concentrated extracts were made ready and stored in a fridge at $4^{\circ} \mathrm{C}$ for further use. Then, a $1: 10$ ratio by volume of the extract-graphene oxide was mixed in a flask and heated at $70^{\circ} \mathrm{C}$ for an hour with continuous stirring using a magnetic stirrer. The jelly-like black solution was taken of the heater and cooled at room temperature. Then, the black structure floating in the clear solution was separated by Whatman number 1 filter paper and washed with distilled water several times. The black paste was dried in the oven at $50^{\circ} \mathrm{C}$ for 5 hours. The dried sample was finely ground and stored for further use [39].

2.4. Synthesis of $\mathrm{Bi}_{2} \mathrm{~S}_{3}-r G O$ Composite. All reagents used in this experiment were analytical grade and used directly without further purification. A simple hydrothermal rout under reflux was used to synthesize $\mathrm{rGO}-\mathrm{Bi}_{2} \mathrm{~S}_{3} .1 .43 \mathrm{~g}$ of the $\mathrm{Bi}_{2} \mathrm{~S}_{3}$ powder was thoroughly dissolved in $50 \mathrm{ml}$ of distilled water, and $2 \mathrm{~g}$ of $\mathrm{rGO}$ was dissolved in the same volume of distilled water in a separate flask. Both mixtures were poured into a $500 \mathrm{ml}$ beaker and sonicated for two hours at room temperature. Then, the mixture was heated under reflux at $100^{\circ} \mathrm{C}$ for 12 hours. The black precipitate was filtered by using Whatman number 1 filter paper and purified by washing with distilled water and ethanol several times. The black paste was dried into a black powder in an oven under $120^{\circ} \mathrm{C}$ for 18 hours. 


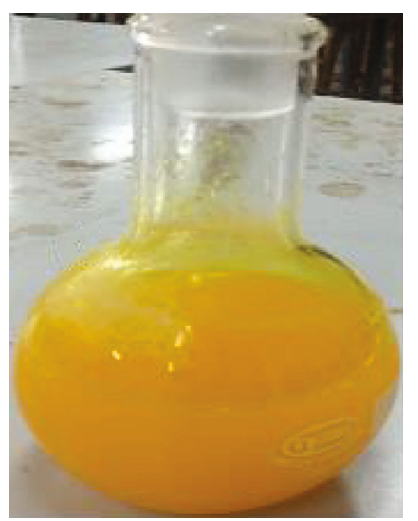

(a)

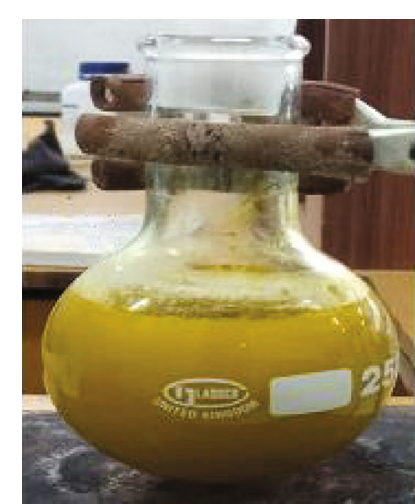

(b)

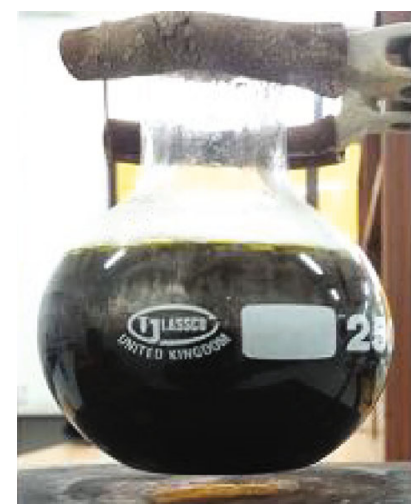

(c)

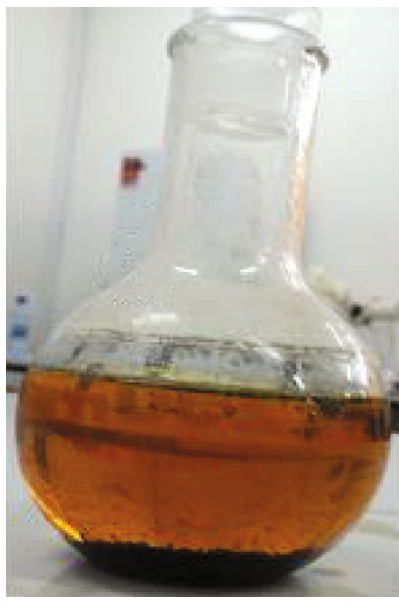

(d)

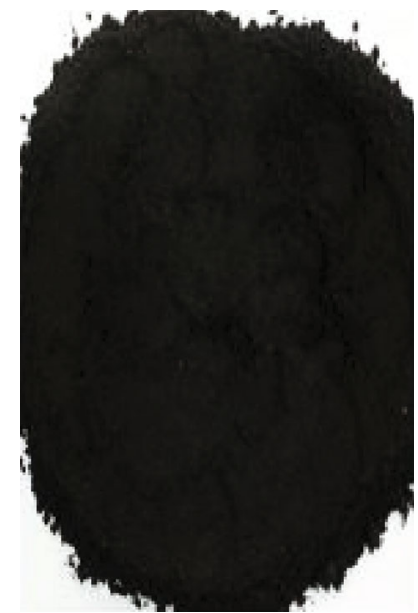

(e)

FIgURE 1: The color change observed during the stepwise synthesis of bismuth sulfide.

2.5. Photocatalysis Study. The photocatalysts were prepared by a simple hydrothermal method, and its performance was tested against the degradation of methylene blue (MB) under visible light irradiation using a $500 \mathrm{~W}$ xenon lamp in the wavelength range $\lambda>42 \mathrm{~nm}$. $125 \mathrm{ml}$ of methylene blue and $5 \mathrm{mg}$ of the catalyst $\mathrm{rGO}-\mathrm{Bi}_{2} \mathrm{~S}_{3}(1: 25$ ratios) were placed in a glass cup reactor $(100 \mathrm{ml})$. The mixture was continuously stirred with ultrasonication for 30 minutes at room temperature to maintain the adsorption-desorption equilibrium. Then after, at a given time interval of irradiation, $5 \mathrm{ml}$ of the reaction mixture liquid was taken out and placed in centrifuge tubes which were later on centrifuged to remove any residual catalyst. The centrifugation and washing of the reaction liquid were done repeatedly using ethanol and water. The UV-Vis spectroscopy analyses were done against the concentrations of residual $\mathrm{MB}$ to check the performance of the catalyst.

2.6. Characterization Techniques. The confirmations of the formation of reduced graphene oxide from graphene oxide and the spectral positions of $\mathrm{Bi}_{2} \mathrm{~S}_{3}$ - $\mathrm{GO}$ were determined by Fourier transform infrared spectroscopy (FTIR, Perkin Elmer, USA). GO- $\mathrm{Bi}_{2} \mathrm{~S}_{3}$ and $\mathrm{rGO}$ pellet were prepared using $\mathrm{KBr}$ as a mulling agent, and the sample was analyzed in the range between $400 \mathrm{~cm}^{-1}$ and $4000 \mathrm{~cm}^{-1}$. X-ray diffraction (XRD) of $\mathrm{Bi}_{2} \mathrm{~S}_{3}, \mathrm{Bi}_{2} \mathrm{~S}_{3}-\mathrm{GO}$, and $\mathrm{rGO}$ was recorded on a Panalytical PW 3040 X'Pert MPD X-ray diffractometer with $\mathrm{Cu}-\mathrm{K} \alpha \mathrm{X}$-ray radiation sources at $40 \mathrm{keV}$ and $30 \mathrm{~mA}$. XRD spectra were recorded to determine the purity and crystallinity of the samples. The optical absorption property of $\mathrm{rGO}$ was examined by ultraviolet-visible spectroscopy (UV-Vis, SM, UV-1600 Maadab-India). The thermogravimetricdifferential thermal analysis (TGA-DTA) was performed with a differential thermal analyzer (DTG-60H, Beijing, China). These tests were operated under a nitrogen atmosphere with a platinum cell at $50 \mathrm{ml} / \mathrm{min}$ flow rate.

\section{Result and Discussion}

\subsection{Synthesis of $\mathrm{Bi}_{2} \mathrm{~S}_{3}$}

3.1.1. Visual Observations. As can be seen in Figure 1, three different colors ( $a, b$, and $c$ ) were dominantly displayed during the stepwise synthesis of bismuth sulfide. Immediately as the solutions of white crystalline salt $\mathrm{BiCl}_{3}$ and the white fine powder $\mathrm{CH}_{4} \mathrm{~N}_{2} \mathrm{~S}$ were mixed, a corn yellow-colored solution was formed as indicated in Figure 1(a). This is the initial step and indication of the generation of sulfide ion as a result of 


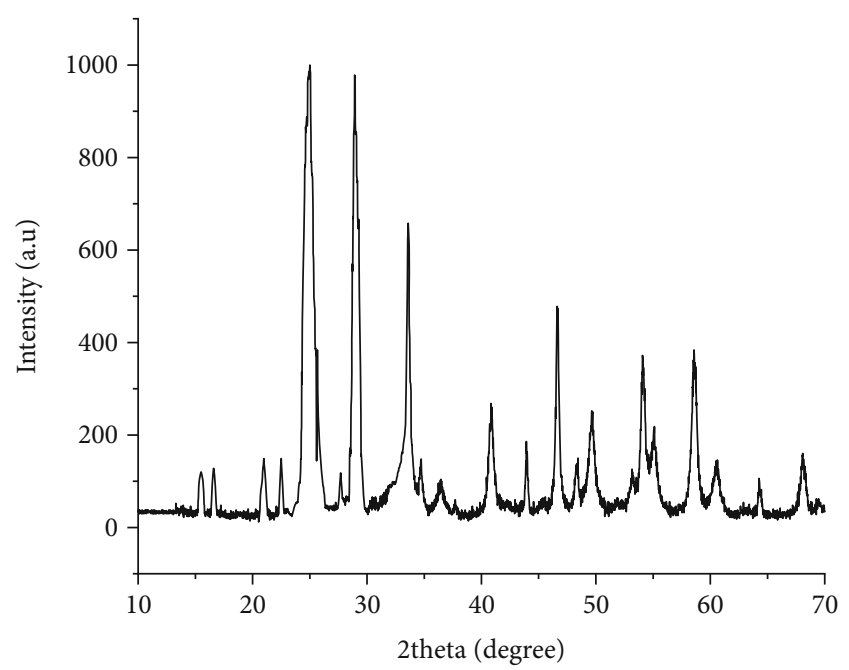

Figure 2: XRD pattern of $\mathrm{Bi}_{2} \mathrm{~S}_{3}$ synthesized from $\mathrm{CH}_{4} \mathrm{~N}_{2} \mathrm{~S}$ and $\mathrm{BiCl}_{3}$ sources.

hydrolysis reaction by the action of $\mathrm{OH}^{-}$in the aqueous solution as shown by the following equation [40]:

$$
\left(\mathrm{NH}_{2}\right)_{2} \mathrm{CS}+2 \mathrm{H}_{2} \mathrm{O} \longrightarrow 2 \mathrm{NH}_{3}+2 \mathrm{CO}_{3}^{2-}+\mathrm{S}^{2-}+2 \mathrm{H}_{2} \mathrm{O}
$$

Upon the addition of Vernonia amygdalina plant extract and heating under continuous stirring, the deep black color was formed as shown in Figure 1(c), through the royal yellow color solution (Figure 1(b)). The brown oily supernatant (Figure 1(d)) was decanted, and a black paste was collected from which the black powder was obtained by oven drying at $100^{\circ} \mathrm{C}$ overnight as depicted in Figure $1(\mathrm{~d})$.

3.1.2. X-Ray Diffraction (XRD). Figure 2 shows the XRD patterns of the as-synthesized $\mathrm{Bi}_{2} \mathrm{~S}_{3}$ nanostructure. All the reflections in the diffraction peaks can be indexed as the orthorhombic structured $\mathrm{Bi}_{2} \mathrm{~S}_{3}$ with lattice constants (of standard data) $a=11.150 \mathrm{~A}, b=11.303 \mathrm{~A}$, and $c=3.981 \mathrm{~A}$ (JCPDS No. 17-0320). The intensities and positions of the peaks are in good agreement with literature values $[7,8$, 28]. Some of the major peaks are ascribed to $020,120,220$, $101,130,021,211,221,301$, and 311 facets, etc.

3.1.3. Thermal Analysis. Figure 1 shows the DTA and TGA curves of the $\mathrm{Bi}_{2} \mathrm{~S}_{3}$ single crystal run from 0 to $1000 \mathrm{~K}$ under $\mathrm{N}_{2}$ gas atmosphere. As can be seen from the graph of TGA in Figure 3, the sample is slightly stable for the temperature range of 0 to $680 \mathrm{~K}$ with a weight loss of $\sim 1-2 \%$ due to the decomposition of some compounds. The significant decomposition of the material with a severe weight loss was observed at around $700 \mathrm{~K}$ increasing continuously with rising temperature up to $1000 \mathrm{~K}$. The maximum weight loss recorded at $1000 \mathrm{~K}$ is $21 \%[41,42]$. This weight loss is attributed to the decomposition of sulfur dioxide $\left(\mathrm{SO}_{2}\right)$, and the remaining product finally turns into $\mathrm{Bi}_{2} \mathrm{O}_{3}$ residue which is confirmed from DTA analysis (Figure 3 ) that gives the endothermic peak at around $910 \mathrm{~K}$. Following the severe weight loss at 700-1000 K, two exothermic peaks and two endothermic peaks were observed from the DTA curve. The maxi-

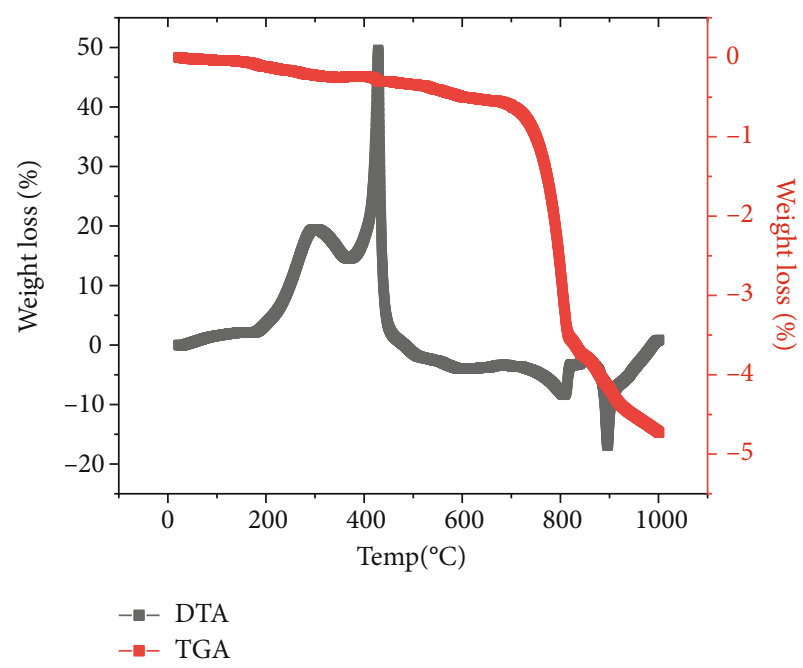

Figure 3: DTA (left side) and TGA (right side) curves of single crystal $\mathrm{Bi}_{2} \mathrm{~S}_{3}$.

mum endothermic peak at around $910 \mathrm{~K}$ means that this temperature is the melting point of $\mathrm{Bi}_{2} \mathrm{~S}_{3}$ which is supposed to be reduced from $1036 \mathrm{~K}$ due to the lowered particle size to the nanoscale.

\subsection{Synthesis of Reduced Graphene Oxide (rGO)}

3.2.1. Visual Observations. As shown in Figures 4(a)-4(c), three main different colors were observed during the stepwise synthesis of rGO. The dark green-colored thick solution as shown in Figure 4(a) is due to the formation of the high oxidizing agent dimanganese heptoxide $\left(\mathrm{Mn}_{2} \mathrm{O}_{7}\right)[43,44]$ from the reaction of $\mathrm{MnO}_{3}^{+}$and $\mathrm{MnO}_{4}^{-}$, and in the meanwhile, the temperature of the solution was increased to $45^{\circ} \mathrm{C}$.

The brown color as indicated in Figure 4(b) was obtained which is one of the confirmations of the formation of the graphene oxide nanostructure. The dark black suspension formed as shown in Figure 4(c) is the sign of GO reduction to produce rGO. The image of powders depicted in Figure $4(\mathrm{~d})$ is $\mathrm{rGO}$.

3.2.2. $U V$-Vis. As a result of the reduction reaction, $\mathrm{GO}$ is deoxygenated and converted into rGO. Less amount of oxygen is detected on rGO, and this is confirmed by the red shift of the peak as shown in Figure 5. Hence, there is a less number of $n-\pi *$ transition in rGO which corresponds to the transition due $\mathrm{C}=\mathrm{O}$ which is very low on $\mathrm{rGO}$. This product is later used to synthesize the bismuth sulfide-reduced graphene oxide nanostructure composite.

The chromatograph profile of the heterostructure rGOBi2S3 recorded by GC-MS is shown in Figure 6. It revealed to be a complex mixture of compounds. The interpretation of the GC-MS spectrum was done based on the NIST library.

In the $\mathrm{UV}-\mathrm{V}$ is analysis of $\mathrm{Bi}_{2} \mathrm{~S}_{3}$ and $\mathrm{rGO}-\mathrm{Bi}_{2} \mathrm{~S}_{3}$ as shown in Figure 7, the peak observed at around 400 and $680 \lambda$ due to sulfide and bismuth disappeared in the case of the heterostructure composite.

3.2.3. XRD. Besides the structural arrangement, the $\mathrm{X}-\mathrm{RD}$ characterization technique is used to monitor the extent of 


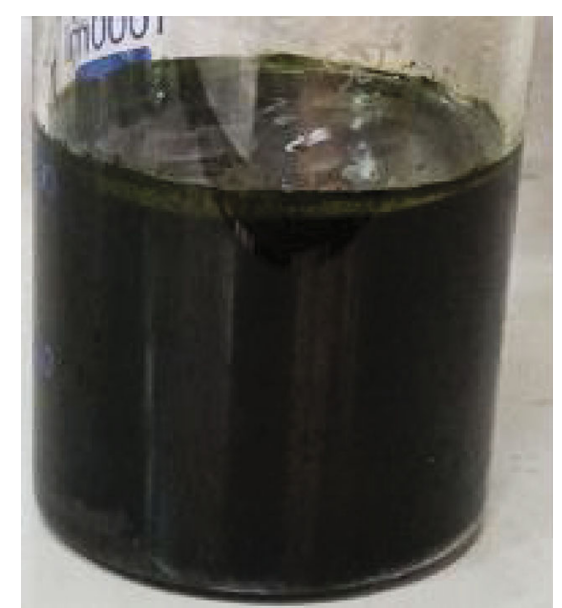

(a)

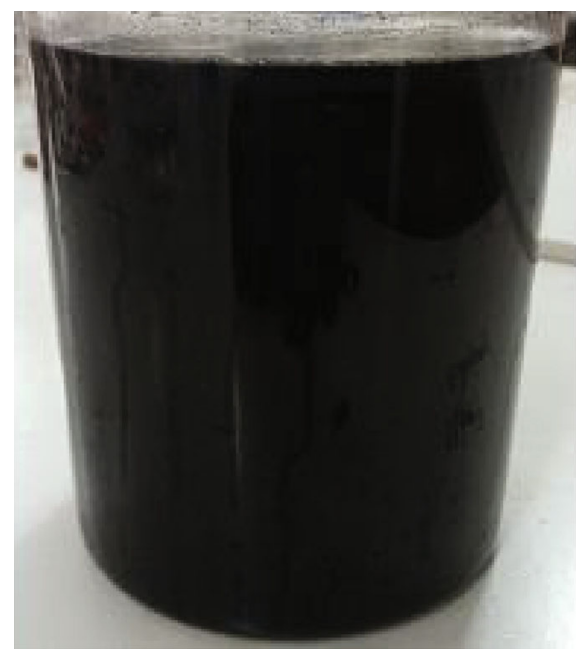

(c)

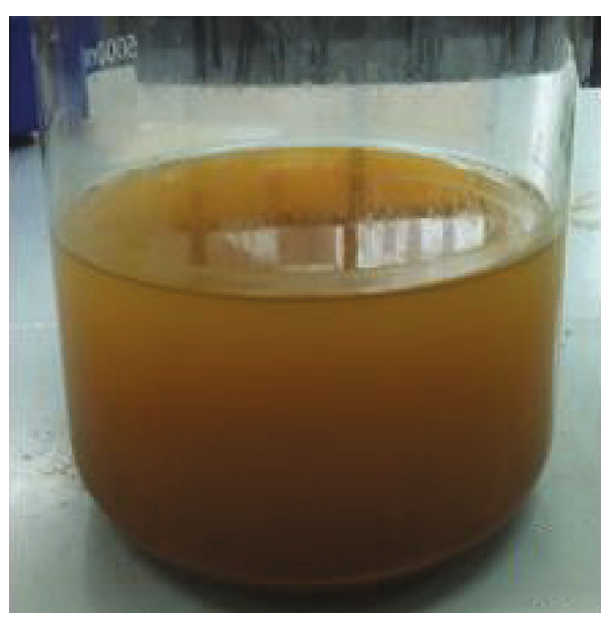

(b)

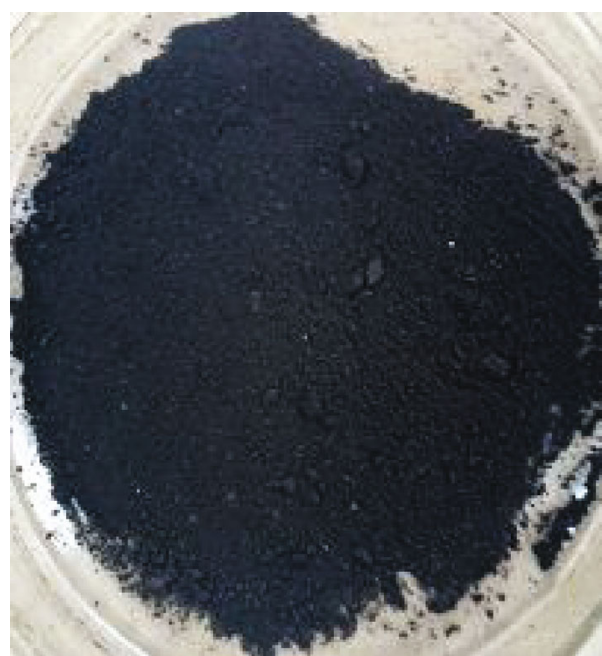

(d)

FIGURE 4: Different colors observed during the stepwise synthesis of rGO.

oxidation and purity of the material under examination. As shown in Figure 8, a peak was observed at around $2 \theta=43^{\circ}$ in $\mathrm{rGO}$ which resulted due to the crystal structure from basal planes slipping out of the alignments. With the green reduction using methanol extracts of Vernonia amygdalina (in Afaan Oromo, it is called Dhebicha) of GO to produce graphene/(rGO), there was a shift in the d-spacing and $2 \theta$ values to $0.36 \mathrm{~nm}$ and $24.5^{\circ}$, respectively, and this result confirmed the successful reduction of GO to graphene/rGO. We have reported the synthesis and green reduction of GO using "Dhebicha" to rGO in our preceding work.

3.2.4. FT-IR. As shown in Figure 9, the structure of the prepared rGO was characterized using FT-IR spectroscopy. The FT-IR record displayed a broad stretching peak at $3408 \mathrm{~cm}^{-1}$ which was attributed to the ${ }^{-} \mathrm{OH}$ of the intercalated residual water molecules and the peak at $1634 \mathrm{~cm}^{-1}$ by the same molecules but due to bending vibration [44] disappeared in rGO. As the oxygen-containing functional groups were removed by the reducing agent, the characteristic absorption peaks of oxide groups decreased significantly, and the $\mathrm{CO}_{2}$ peak at around $2640 \mathrm{~cm}^{-1}$ vanished indicating the successful

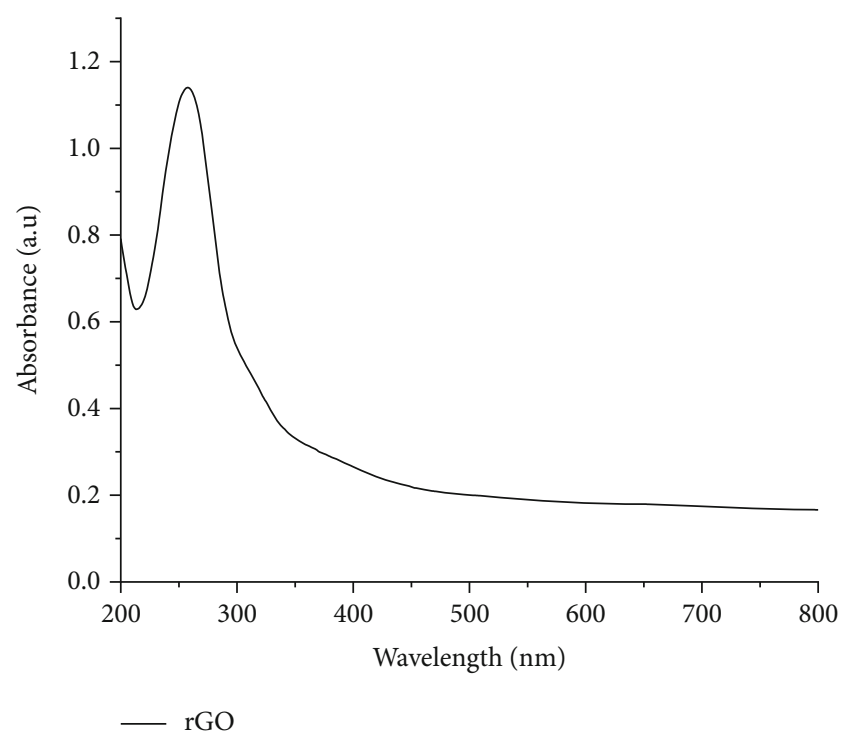

FIgURe 5: UV-Vis spectra record of rGO. 


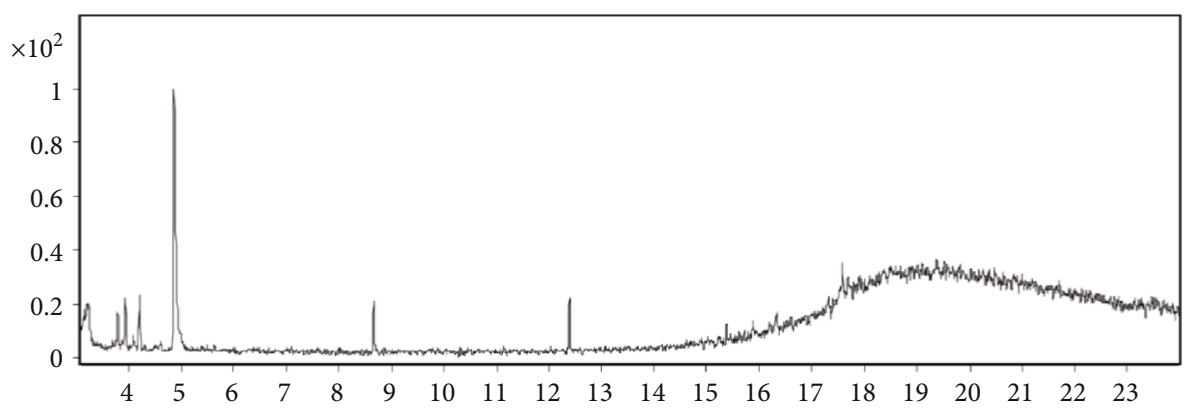

FIgURE 6: GC-MS chromatogram of $\mathrm{rGO}-\mathrm{Bi}_{2} \mathrm{~S}_{3}$.

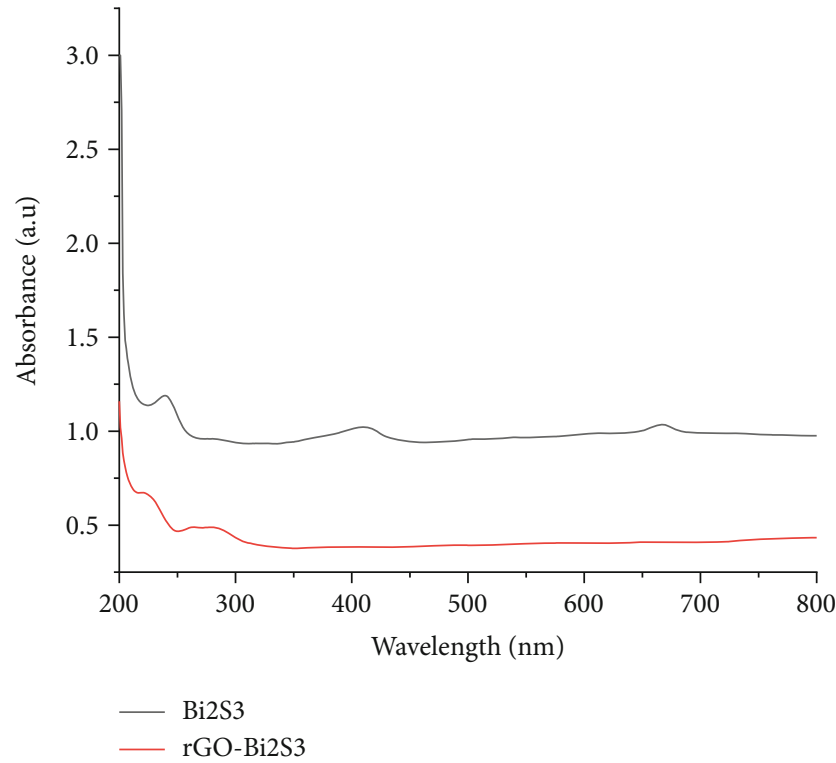

Figure 7: UV-Vis spectra record of $\mathrm{Bi}_{2} \mathrm{~S}_{3}$ and $\mathrm{rGO}-\mathrm{Bi}_{2} \mathrm{~S}_{3}$.

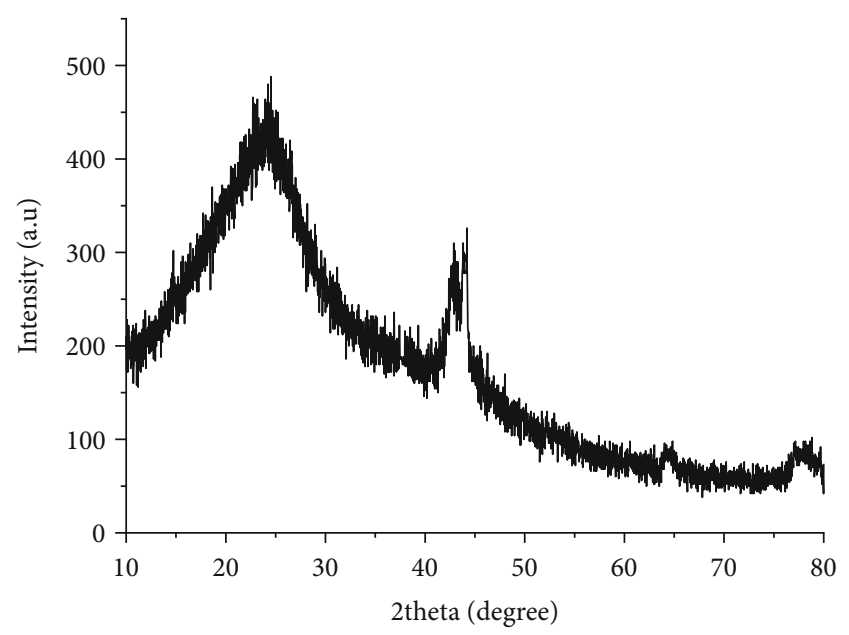

Figure 8: X-ray diffraction pattern of rGO.

reduction of GO. The compounds obtained from Vernonia amygdalina (VA) by solvent extraction using methanol as a solvent were used to reduce GO to rGO. Most of the peaks related to carbonyl, carboxyl, and hydroxyl of water disappeared in the spectra of rGO. The sharp band formed at

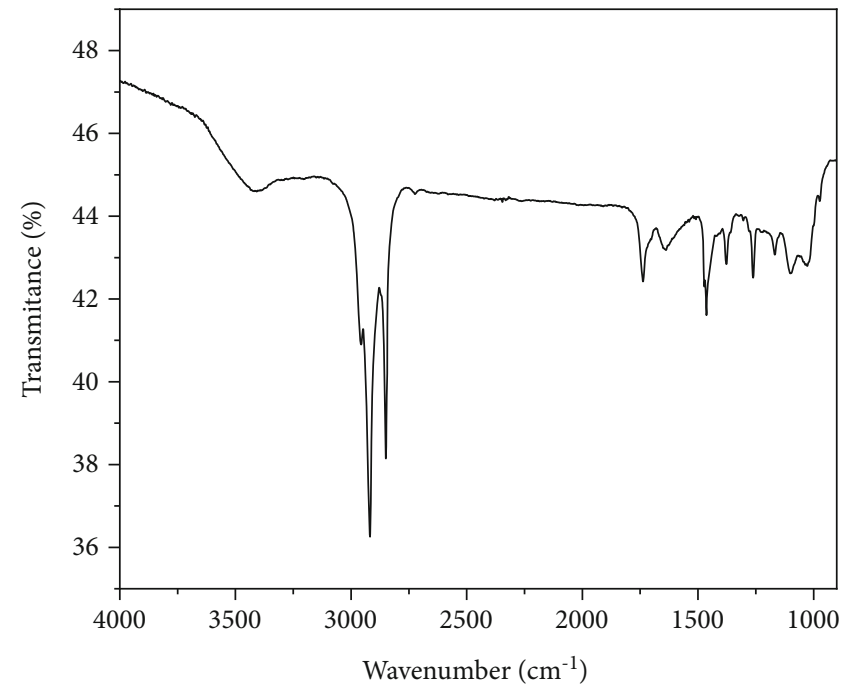

FIGURE 9: FT-IR spectra record of rGO obtained by reduction of GO by VA.

$1570 \mathrm{~cm}^{-1}$ was attributed to $\mathrm{C}=\mathrm{C}$ stretching. The absorption peak formed at 1222 and $1051 \mathrm{~cm}^{-1}$ as a result of the stretching vibration of the epoxide and alkoxy $(\mathrm{C}-\mathrm{O})$ groups, respectively, in $\mathrm{GO}$ is not observed in $\mathrm{rGO}$ which is also the indicator of the successful reduction of GO. Hence, the FT-IR spectra record shown in Figure 7 confirms the complete reduction of $\mathrm{GO}$ to $\mathrm{rGO}$, and the synthesized $\mathrm{rGO}$ was used to manufacture the rGO- $\mathrm{Bi}_{2} \mathrm{~S}_{3}$ nanostructure composite for the decomposition of methylene blue in the presence of visible light irradiation.

\section{3. $B i_{2} S_{3}-r G O$ Synthesis}

3.3.1. $X R D$. Here, the powder X-ray diffraction (XRD) is used to determine the phase structure of the as-prepared rGO- $\mathrm{Bi}_{2} \mathrm{~S}_{3}$ composite. Figure 10 shows the XRD patterns of $\mathrm{rGO}-\mathrm{Bi}_{2} \mathrm{~S}_{3}$ composites.

The result obtained for $\mathrm{rGO}-\mathrm{Bi}_{2} \mathrm{~S}_{3}$ is similar to the $\mathrm{XRD}$ pattern of $\mathrm{Bi}_{2} \mathrm{~S}_{3}$ which implies that the weak XRD spectra of rGO at $2 \theta=24.5^{\circ}$ is shielded by the strong peak intensities of $\mathrm{Bi}_{2} \mathrm{~S}_{3}$ at around $2 \theta=25^{\circ}$. The peaks observed at $2 \theta>40^{\circ}$ in $\mathrm{Bi}_{2} \mathrm{~S}_{3}$ disappeared in the case of composites but get relatively narrower which is attributed to the degree of crystallinity and purity of rGO- $\mathrm{Bi}_{2} \mathrm{~S}_{3}$. As determined from TGA analysis, the amount of rGO in the composite is lower that its peak is 


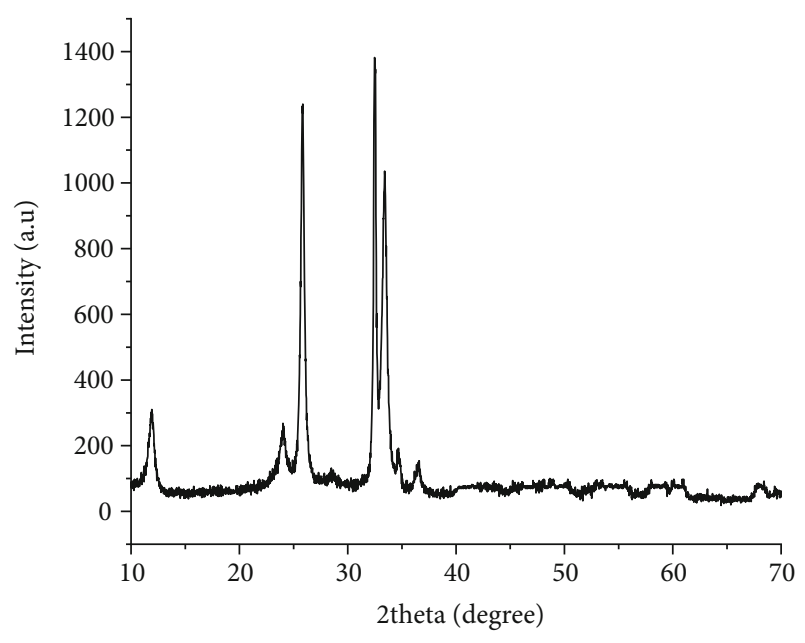

FIGURE 10: XRD pattern of $\mathrm{rGO}-\mathrm{Bi}_{2} \mathrm{~S}_{3}$ nanostructure composite.
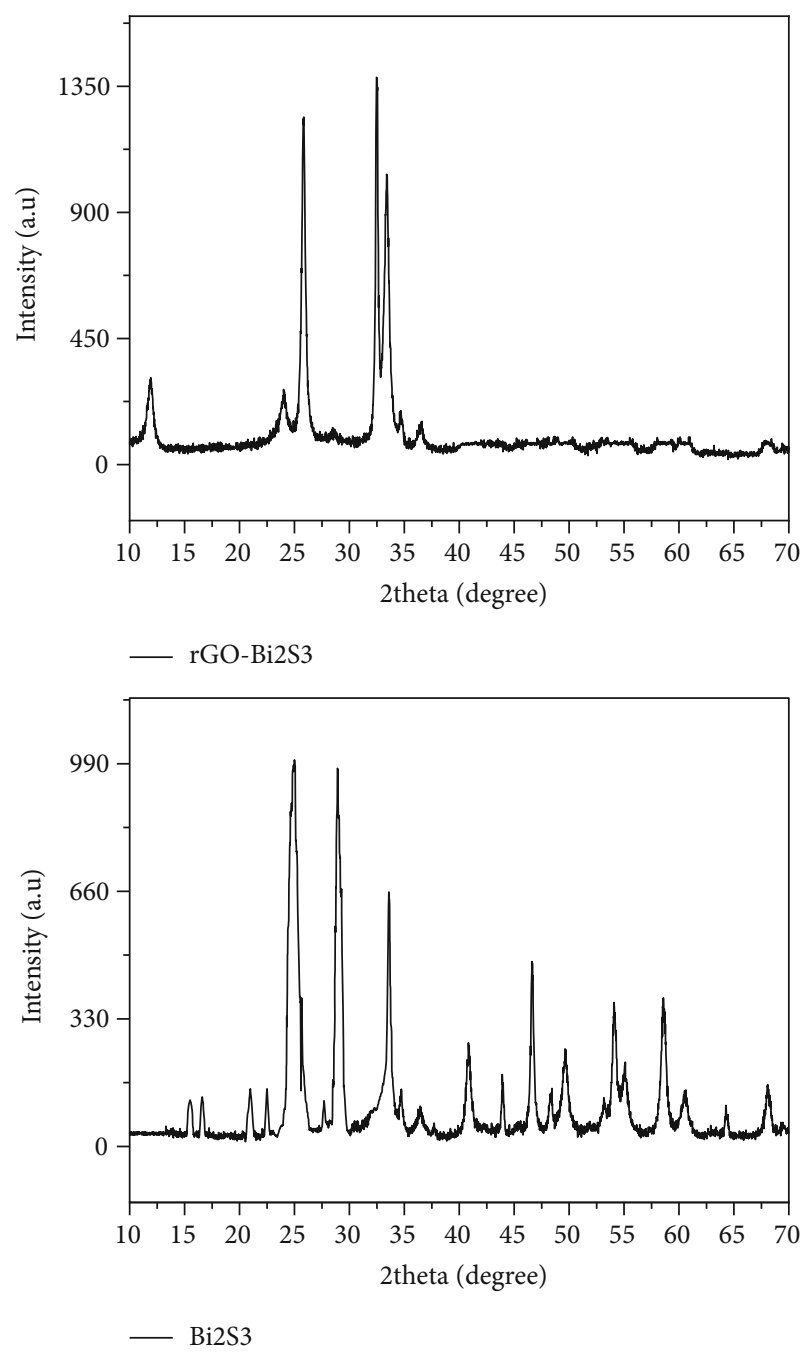

FIGURE 11: XRD pattern of $\mathrm{Bi}_{2} \mathrm{~S}_{3}$ and $\mathrm{rGO}-\mathrm{Bi}_{2} \mathrm{~S}_{3}$ stacked vertically.

dominated by the peak of $\mathrm{Bi}_{2} \mathrm{~S}_{3}$. In Figure 11, the XRD results of $\mathrm{Bi}_{2} \mathrm{~S}_{3}$ and $\mathrm{rGO}-\mathrm{Bi}_{2} \mathrm{~S}_{3}$ were stacked vertically to compare their crystallinity.

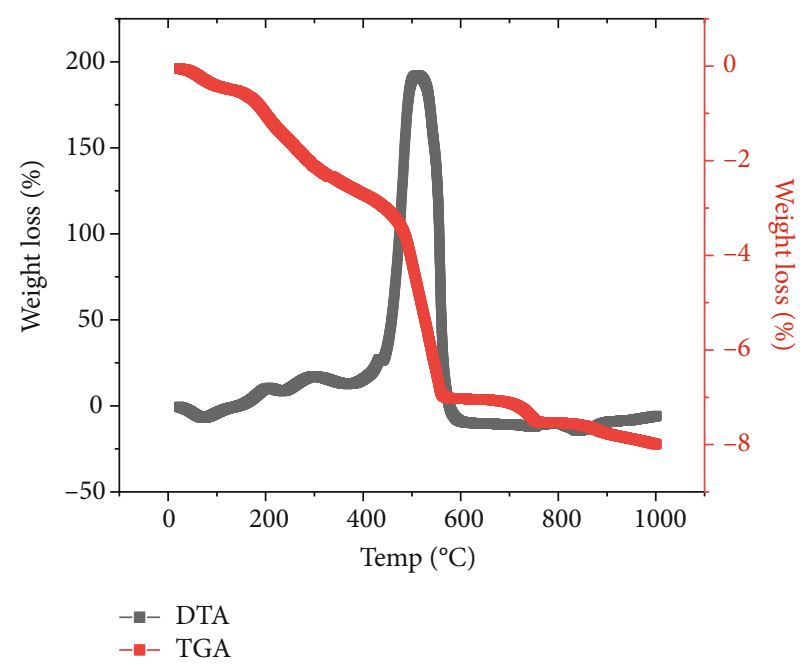

FIgURE 12: Thermal analysis results of $\mathrm{rGO}-\mathrm{Bi}_{2} \mathrm{~S}_{3}$ NSs composite.

3.3.2. Thermal Analysis. From the differential thermogravimetric analysis result shown in Figure 9 (black line), the oxidative decomposition temperature of $\mathrm{rGO}-\mathrm{Bi}_{2} \mathrm{~S}_{3}$ is $450 \mathrm{~K}$. This value is less than the DTA value of pure rGO which is equal to $570 \mathrm{~K}$ [45]. The decomposition of rGO is enhanced when a metal sulfide is bonded to it because of the catalytic effects of the metal sulfide nanoparticles. Hence, the lower decomposition temperature of rGO in the composite is attributed to the catalytic effects of the $\mathrm{Bi}_{2} \mathrm{~S}_{3}$ which confirms the anchoring of $\mathrm{Bi}_{2} \mathrm{~S}_{3}$ to the surface of rGO to form the $\mathrm{rGO}-\mathrm{Bi}_{2} \mathrm{~S}_{3}$ composite. The decomposition peak observed from the DTA graph for $\mathrm{rGO}-\mathrm{Bi}_{2} \mathrm{~S}_{3}$ is $450 \mathrm{~K}$. As can be seen from the TGA analysis of $\mathrm{Bi}_{2} \mathrm{~S}_{3}$ (Figure 3), maximum decomposition of the materials started at $700 \mathrm{~K}$ which is much greater than the value for the composite $\mathrm{rGO}-\mathrm{Bi}_{2} \mathrm{~S}_{3}$ which is equal to $430 \mathrm{~K}$ (Figure 12, red line). The lowered decomposition temperature in the case of the composite is attributed to the presence of oxygen that favors the decomposition rate with low temperature.

3.3.3. FT-IR. As shown in Figure 13, the relatively smaller band unlike that of the broad peak in GO formed at $3460 \mathrm{~cm}^{-1}$ is attributed to the O-H functional group of the residual water stretching, and the band observed at $1640 \mathrm{~cm}^{-1}$ is due to the bending vibration of the same group [46]. The relatively wide absorption peak formed at $1090 \mathrm{~cm}^{-}$ ${ }^{1}$ is attributed to the interaction between the rGO and the $\mathrm{Bi}_{2} \mathrm{~S}_{3}$ nanostructure composite [47].

\subsection{Photocatalytic Activity}

3.4.1. Photocatalytic Degradation of Methylene Blue. One of the organic dyes most extensively used in almost all textile industries is methylene blue (MB), but it often pollutes the environment [48]. Thus, in this study, we tried to examine the photocatalytic degradation performance of as-prepared rGO- $\mathrm{Bi}_{2} \mathrm{~S}_{3}$ against this important as well as serious pollutant $\mathrm{MB}$ under simulated visible light irradiation. The photocatalytic degradation of methylene blue (MB) was investigated in the absence and presence of as-synthesized $\mathrm{rGO}-\mathrm{Bi}_{2} \mathrm{~S}_{3}$ 


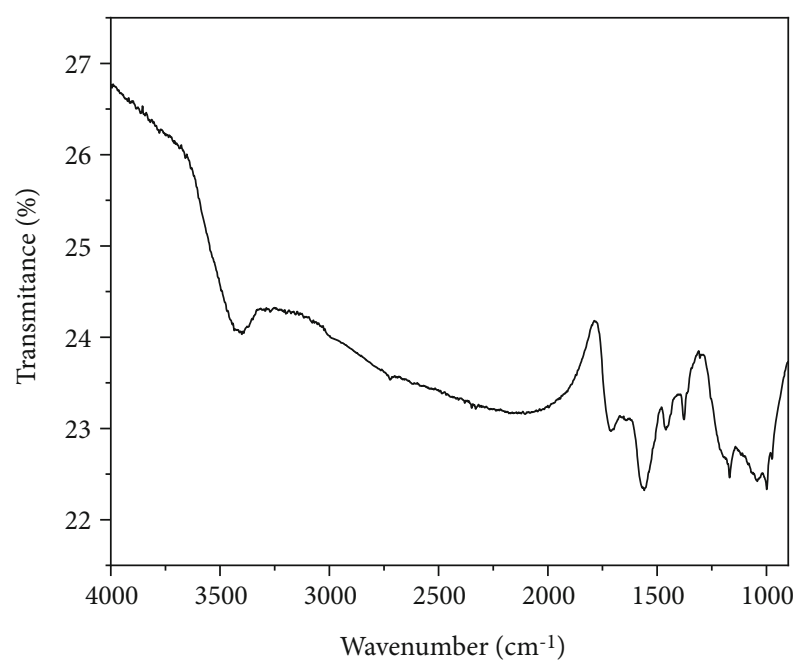

FIGURE 13: FT-IR spectral records of the composite NSs and rGO$\mathrm{Bi}_{2} \mathrm{~S}_{3}$.

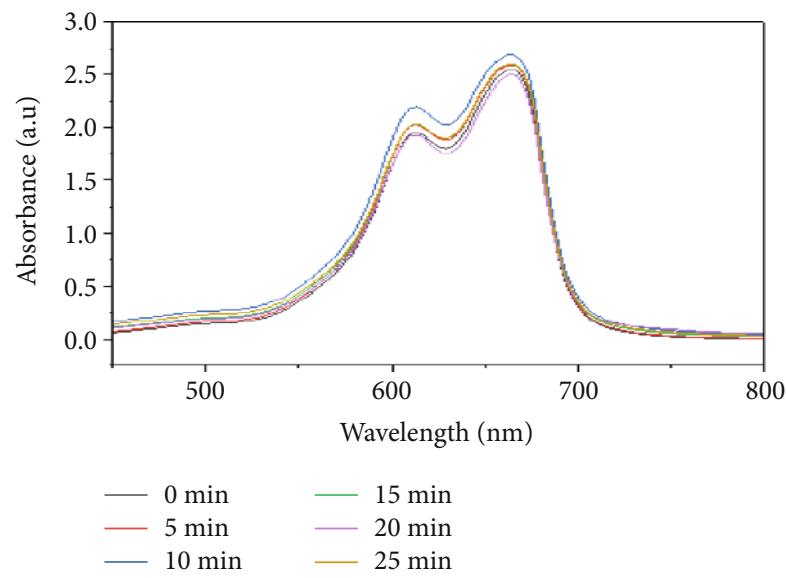

FIGURE 14: Degradation tests of MB in the absence of the catalyst under visible light.

composite nanostructure (NS) catalyst under visible light irradiation. As shown in Figure 11 in the photodegradation spectra of $M B$, there is no significant change observed in the intensity of MB in the absence of the catalyst. The maximum wavelength $\left(\lambda_{\max }\right)$ of MB is $664 \mathrm{~nm}$, and the red- and blueshifts were not observed with the prolonged irradiation in the absence of $\mathrm{rGO}-\mathrm{Bi}_{2} \mathrm{~S}_{3}$, but there was insignificant intensity change (with a maximum decrease of $7 \%$ ) at 20 minutes. Hence, the dye does not degrade when exposed to the light in the absence of a catalyst. The decrease in the intensity of the spectra is not consistent with the time of irradiation in the absence of the catalyst as can be observed in Figure 14. Hence, the use of a catalyst is mandatory to degrade dyes to prevent pollution in the environment.

It has been reported that graphene oxide (GO) significantly enhanced the efficiency of $\mathrm{Bi}_{2} \mathrm{~S}_{3}$ in the degradation of dyes (methylene blue) [32]. As shown below in Figure 15, rGO displayed superior enhancement for the dye degradation in this study. The degradations started immediately as a $1: 25$

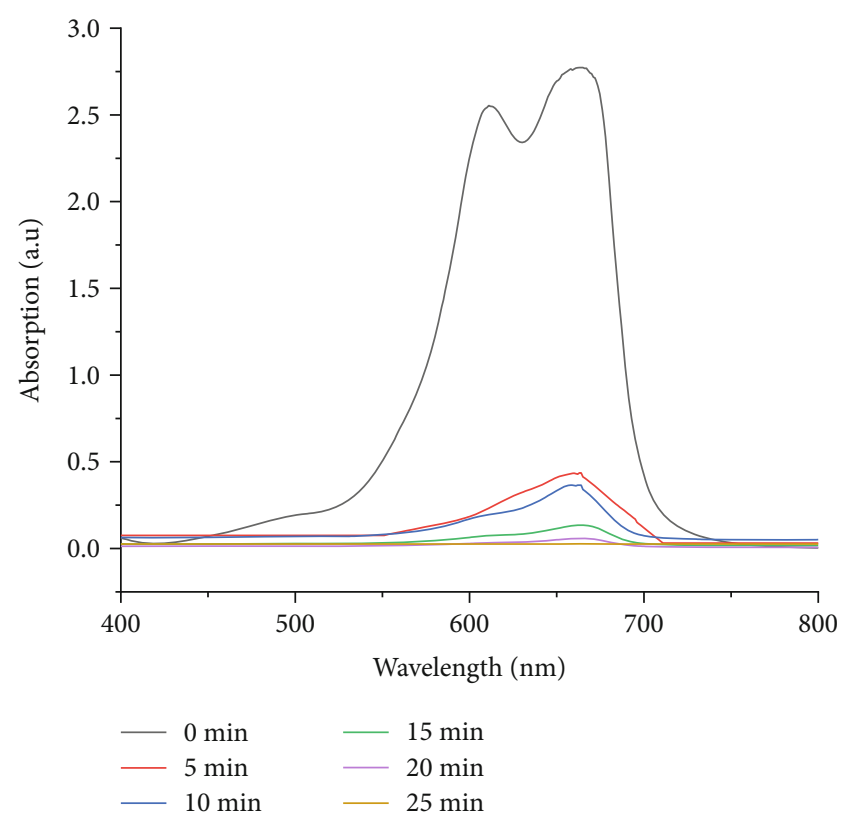

Figure 15: Degradation tests of MB in the presence of the catalyst under visible light.

ratio of the catalyst-to-dye mixture was subjected to visible radiation. The study was carried for a total of 25 minutes.

The maximum intensity of MB after 5 minutes of irradiation was decreased to 0.43561 . The degradation efficiency was recorded to be $84 \%, 86 \%, 95 \%, 97 \%$, and $99 \%$ at 5,10 , 15,20 , and 25 minutes, respectively. Hence, $\mathrm{rGO}-\mathrm{Bi}_{2} \mathrm{~S}_{3}$ is the best composite with $99 \%$ degradation efficiency. Figure 16 shows the degradation percentage of the pollutant versus the time taken. It is reported in many works that the activity of the photocatalyst depends on the separation and transfer of charge carriers generated by irradiation that provoke the formation of active species of hydroxyl $(\cdot \mathrm{OH})$ and superoxide $\left(\cdot \mathrm{O}_{2}{ }^{-}\right)$radicals. These facilitate degradation of the organic pollutant adhered onto the photocatalyst surface [27, 49]. According to kinetics analysis, the photocatalytic degradation of organic pollutants obeys a Langmuir isotherm mechanisms and follows a quasi-first-order reaction with the photocatalytic degradation rate defined by the following equation:

$$
r=-\frac{d C_{t}}{d_{t}}=K_{\mathrm{obs}} C_{t}
$$

The durability and reusability are also another way of measuring the performance of a catalyst.

The photocatalyst after each run was collected, washed with distilled water, dried at $80^{\circ} \mathrm{C}$, and used for the successive new run. The photocatalytic activity of $\mathrm{rGO}-\mathrm{Bi}_{2} \mathrm{~S}_{3}$ nanostructure composites exhibited insignificant change (decrease) after running for five cycles as shown in Figure 17 for a 25 -minute retention time, confirming that the potentials of $\mathrm{rGO}-\mathrm{Bi}_{2} \mathrm{~S}_{3}$ to be a stable catalyst that can be used several times. 


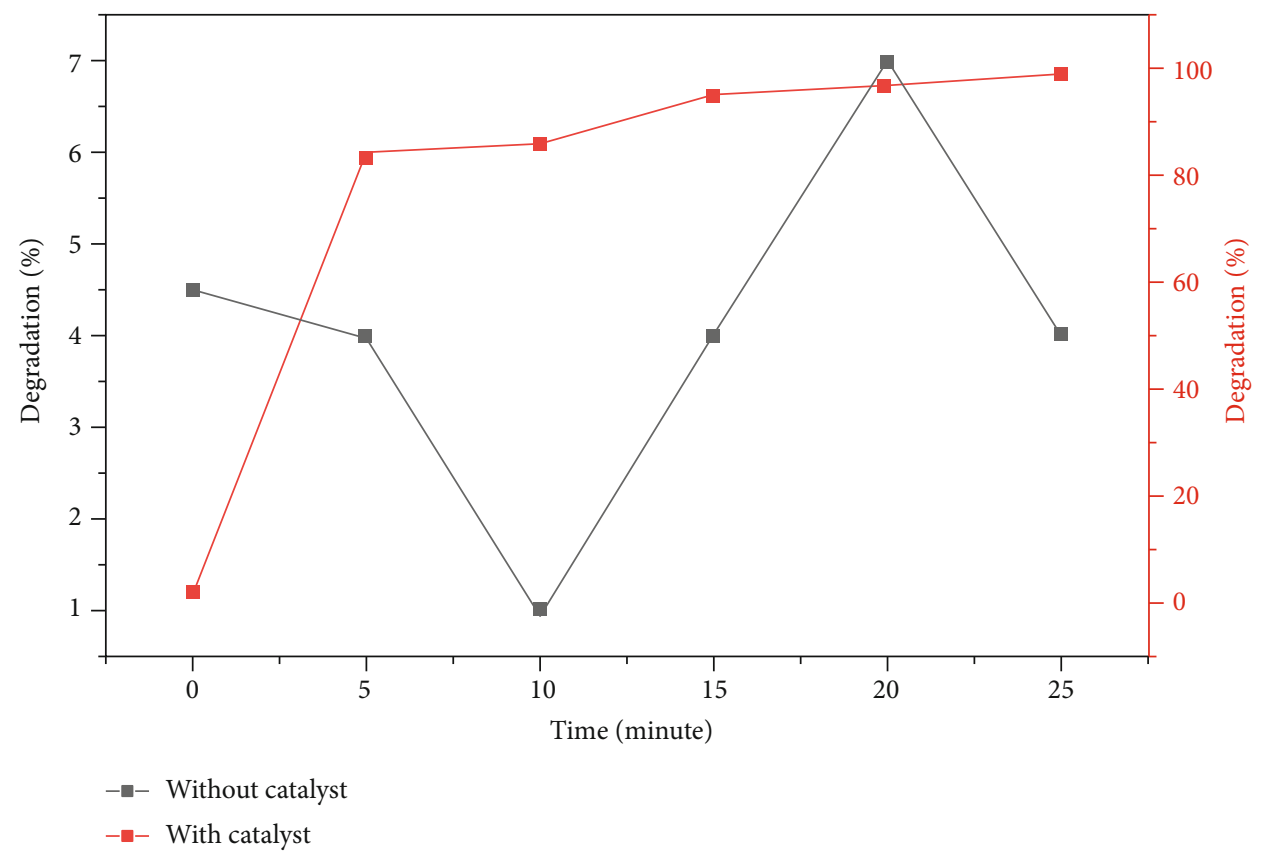

Figure 16: The degradation of methylene blue under visible light irradiation with and without a catalyst at different time intervals.

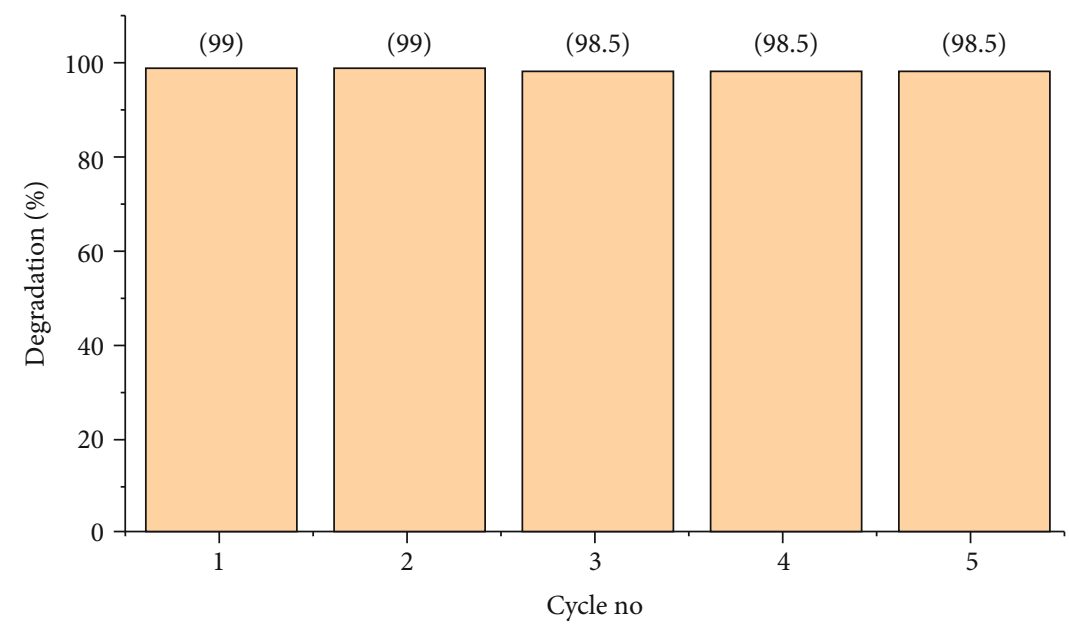

Figure 17: The cyclic degradation efficiency of $\mathrm{rGO}-\mathrm{Bi}_{2} \mathrm{~S}_{3}$ composite against MB.

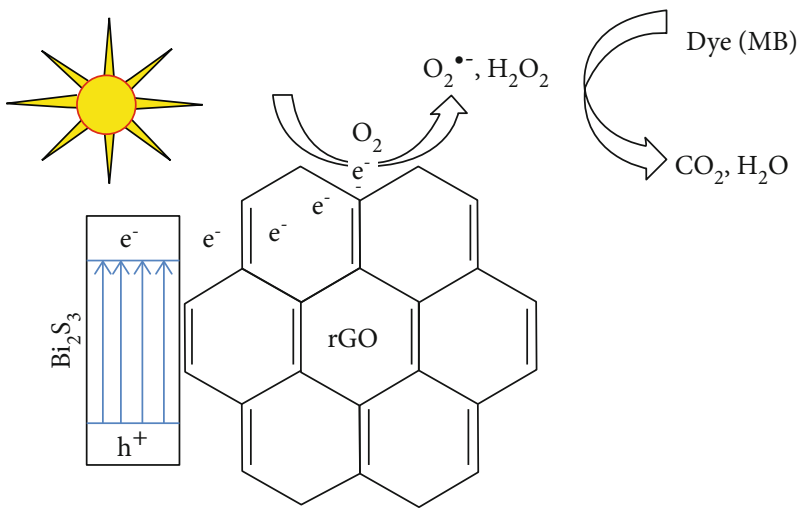

Figure 18: Mechanisms of Photodegradation by rGO-Bi2S3.
3.5. Mechanism of Photodegradation of Dyes. The generation of the charge carriers (electron hole) by the semiconductor during irradiation by visible light was the initiator of the photodegradation reaction. The charge intertransfer mechanism through the $\mathrm{rGO}-\mathrm{Bi}_{2} \mathrm{~S}_{3}$ composite nanostructure during the degradation of the $\mathrm{MB}$ dye is shown in Figure 18. When the semiconductor is irradiated by sunlight, it generates an $\mathrm{e}^{-}-\mathrm{h}^{+}$pair which is stabilized by the electron acceptor rGO. This graphene material prevents the recombination of the charge carrier by accepting an electron from $\mathrm{Bi}_{2} \mathrm{~S}_{3}$ favoring the continuous generation of the charge carrier. Reduced graphene oxide accepts the electron from the semiconductor by two different ways unlike GO. One is by using its peripheral residual oxygen and the second is by the positive polarity formed at its edges due to the delocalized electron on the materials. 
rGO inhibits charge carrier recombination by reducing the band gap so that the energy absorption efficiency of rGO- $\mathrm{Bi}_{2} \mathrm{~S}_{3}$ is increased which in turn results in the accelerated generation of the $\mathrm{e}^{-} \mathrm{h}^{+}$pair. Therefore, with the effective separation of charge carriers upon the irradiation of the $\mathrm{rGO}-\mathrm{Bi}_{2} \mathrm{~S}_{3}$ composite with visible light, the continuously generated electrons participated in the decomposition of $\mathrm{O}_{2}$ and $\mathrm{H}_{2} \mathrm{O}_{2}$ to generate the active species such as $\mathrm{O}_{2}{ }^{--}$and $\cdot \mathrm{OH}$ for the degradation of the dyes.

\section{Conclusions}

The heterogeneous photocatalyst $\mathrm{rGO}-\mathrm{Bi}_{2} \mathrm{~S}_{3}$ was synthesized from $\mathrm{Bi}_{2} \mathrm{~S}_{3}$ and $\mathrm{rGO}$ by a single-step refluxed hydrothermal method. $\mathrm{Bi}_{2} \mathrm{~S}_{3}$ was synthesized from thiourea and bismuth chloride in the presence of methanol extracted VA. The reduction of GO to $\mathrm{rGO}$ was also done by using these multifunctional compounds obtained from VA by the methanol extraction method. All the synthesized materials were characterized, and their formations were confirmed. With two groups of samples, comparative studies were performed on the degradation rate of $\mathrm{MB}$ under visible light irradiation. Samples with and without the presence of the catalyst were considered. A group of samples with the presence of a catalyst were prepared by adding $5 \mathrm{mg}$ of $\mathrm{rGO}-\mathrm{Bi}_{2} \mathrm{~S}_{3}$ to $125 \mathrm{ml}$ of the $\mathrm{MB}(1: 25)$ ratio and sonicated for 30 minutes to obtain the adsorption desorption equilibrium. After being subjected to visible light, $5 \mathrm{ml}$ of the sample was taken at 5-minute intervals and collected in a centrifuge tube, which was later on centrifuged, and UV-Vis analysis was done for the performance test. $2 \%, 84 \%, 86 \%, 95 \%, 97 \%$, and $99 \%$ degradations were recorded for $0,5,10,15,20$, and 25 minutes, respectively. This degradation performance capacity is confirmed to be constant by repeating the test for five times, and the maximum average is $99 \%$ for a 25 -minute retention time. The maximum degradation value recorded under visible light irradiation of $\mathrm{MB}$ in the absence of a catalyst was $7 \%$. The reusability and durability test made confirmed that the catalyst can be reused continuously for several times without decrease in capacity. The catalyst regenerated from the solution by washing with distilled water several times was reused for catalysis of $\mathrm{MB}$ for five cycles with the insignificant decrease in the degradation capacity. From the result obtained, the maximum decrease in the degradation capacity by percent for a 25 -minute retention time was $7 \%$.

\section{Data Availability}

All data we used in this study were included in the main text.

\section{Conflicts of Interest}

The authors declare that there are no conflicts of interest to disclose.

\section{Acknowledgments}

The authors would like to acknowledge "ASTU" for the support provided in the characterization of the sample.

\section{References}

[1] Q. Wu, W. S. Miao, Y. Du Zhang, H. J. Gao, and D. Hui, "Mechanical properties of nanomaterials: a review," Nanotechnology Reviews, vol. 9, no. 1, pp. 259-273, 2020.

[2] I. Khan, K. Saeed, and I. Khan, "Nanoparticles: properties, applications and toxicities," Arabian Journal of Chemistry, vol. 12, no. 7, pp. 908-931, 2019.

[3] G. Zhu and P. Liu, "Low-temperature urea-assisted hydrothermal synthesis of Bi2S3nanostructures with different morphologies," Crystal Research and Technology, vol. 44, no. 7, pp. 713-720, 2009.

[4] L. B. Matyushkin, O. A. Ryzhov, O. A. Aleksandrova, and V. A. Moshnikov, "Synthesis of metal and semiconductor nanoparticles in a flow of immiscible liquids," Semiconductors, vol. 50, no. 6, pp. 844-847, 2016.

[5] K. M. Gupta and N. Gupta, Advanced Semiconducting Materials and Devices, Springer Journal, 2015.

[6] Z. Liu, J. Fang, W. Xu, X. Xu, S. Wu, and X. Zhu, "Low temperature hydrothermal synthesis of $\mathrm{Bi}_{2} \mathrm{~S}_{3}$ nanorods using $\mathrm{BiOI}$ nanosheets as self-sacrificing templates," Materials Letters, vol. 88, pp. 82-85, 2012.

[7] H. Wang, J. J. Zhu, J. M. Zhu, and H. Y. Chen, "Sonochemical method for the preparation of bismuth sulfide nanorods," The Journal of Physical Chemistry. B, vol. 106, no. 15, pp. 38483854, 2002.

[8] X. H. Liao, H. Wang, J. J. Zhu, and H. Y. Chen, "Preparation of $\mathrm{Bi}_{2} \mathrm{~S}_{3}$ nanorods by microwave irradiation," Materials Research Bulletin, vol. 36, no. 13-14, pp. 2339-2346, 2001.

[9] Z. H. Ge, P. Qin, D. He et al., "Highly enhanced thermoelectric properties of Bi/Bi2S3Nanocomposites," ACS Applied Materials \& Interfaces, vol. 9, no. 5, pp. 4828-4834, 2017.

[10] H. Zou, D. M. Rowe, and S. G. K. Williams, "Peltier effect in a co-evaporated $\mathrm{Sb}_{2} \mathrm{Te}_{3}(\mathrm{P})-\mathrm{Bi}_{2} \mathrm{Te}_{3}(\mathrm{~N})$ thin film thermocouple," Thin Solid Films, vol. 408, no. 1-2, pp. 270-274, 2002.

[11] W. Liu, K. C. Lukas, K. McEnaney, S. Lee, Q. Zhang, C. P. Opeil et al., "Studies on the $\mathrm{Bi}_{2} \mathrm{Te}_{3}-\mathrm{Bi}_{2} \mathrm{Se}_{3}-\mathrm{Bi}_{2} \mathrm{~S}_{3}$ system for mid-temperature thermoelectric energy conversion," Energy \& Environmental Science, vol. 6, pp. 552-560, 2013.

[12] A. Boulouz, A. Giani, B. Sorli, L. Koutti, A. Massaq, and F. Pascal-Delannoy, "Fabrication of thermoelectric sensor and cooling devices based on elaborated bismuth-telluride alloy thin films," Journal of Materials, vol. 2014, 8 pages, 2014.

[13] X. Yuan, X. Wu, Z. Feng, W. Jia, X. Zheng, and C. Li, "Facile synthesis of heterojunctioned $\mathrm{ZnO} / \mathrm{Bi}_{2} \mathrm{~S}_{3}$ nanocomposites for enhanced photocatalytic reduction of aqueous $\mathrm{Cr}(\mathrm{VI})$ under visible-light irradiation," Catalysts, vol. 9, no. 7, p. 624, 2019.

[14] F. Perreault, A. Fonseca De Faria, and M. Elimelech, "Environmental applications of graphene-based nanomaterials," Chemical Society Reviews, vol. 44, no. 16, pp. 5861-5896, 2015.

[15] Z. Carmen and S. Daniel, "Textile organic dyes-characteristics, polluting effects and separation/elimination procedures from industrial effluents - a critical overview, Org. Pollut. Ten Years After Stock," Conv. - Environ. Anal. Updat, pp. 534, 2012. 
[16] A. M. Le Marechal, B. Krianec, S. Vajnhandl, and J. Volmajer, "Textile finishing industry as an important source of organic pollutants, Org. Pollut. Ten Years After Stock," Conv. - Environ. Anal. Updat, pp. 9-28, 2012.

[17] G. Luongo, "A potential source for human exposure and environmental pollution ( $\mathrm{PhD}$ dissertation, Department of Environmental Science and Analytical Chemistry, Stockholm University)," Chemicals in Textiles, 2015.

[18] I. Nassar, V. V. Osipova, G. Safiullin, V. Lobkov, and Y. Galyametdinov, "Preparation of II-VI semiconductors nanoparticles and investigation of their photophysical properties," International Journal of Green Nanotechnology: Biomedicine, vol. 3, no. 1, pp. 22-36, 2011.

[19] R. Piras, M. Aresti, M. Saba et al., "Colloidal synthesis and characterization of Bi2S3nanoparticles for photovoltaic applications," Journal of Physics Conference Series, vol. 566, p. 012017, 2014.

[20] T. Wu, X. Zhou, H. Zhang, and X. Zhong, " $\mathrm{Bi}_{2} \mathrm{~S}_{3}$ nanostructures: a new photocatalyst," Nano Research, vol. 3, no. 5, pp. 379-386, 2010.

[21] H. H. Huang, J. Chen, Y. Z. Meng et al., "Synthesis and characterization of $\mathrm{Bi}_{2} \mathrm{~S}_{3}$ composite nanoparticles with high X-ray absorption," Materials Research Bulletin, vol. 48, no. 10, pp. 3800-3804, 2013.

[22] D. Ghanbari, M. Salavati-Niasari, S. Karimzadeh, and $\mathrm{S}$. Gholamrezaei, "Hydrothermal synthesis of $\mathrm{Bi}_{2} \mathrm{~S}_{3}$ nanostructures and ABS-based polymeric nanocomposite," Journal of Nanostructures, vol. 4, pp. 227-232, 2014.

[23] D. Zhao, W. Wang, W. Zong et al., "Synthesis of $\mathrm{Bi}_{2} \mathrm{~S}_{3} / \mathrm{BiVO}_{4}$ heterojunction with a one-step hydrothermal method based on $\mathrm{pH}$ control and the evaluation of visible-light photocatalytic performance," Materials, vol. 10, no. 8, p. 891, 2017.

[24] K. Sridharan, S. Shenoy, S. G. Kumar, C. Terashima, A. Fujishima, and S. Pitchaimuthu, "Advanced twodimensional heterojunction photocatalysts of stoichiometric and non-stoichiometric bismuth oxyhalides with graphitic carbon nitride for sustainable energy and environmental applications," Catalysts, vol. 11, no. 4, p. 426, 2021.

[25] M. Samadi, M. Zirak, A. Naseri, E. Khorashadizade, and A. Z. Moshfegh, "Recent progress on doped $\mathrm{ZnO}$ nanostructures for visible-light photocatalysis," Thin Solid Films, vol. 605, pp. 219, 2016.

[26] Q. Su, Y. Li, R. Hu, F. Song, S. Liu, C. Guo et al., "Heterojunction photocatalysts based on 2D materials: the role of configuration," Advanced Sustainable Systems, vol. 4, pp. 1-19, 2020.

[27] V. Stavila, K. H. Whitmire, and I. Rusakova, "Supporting information: synthesis of $\mathrm{Bi}_{2} \mathrm{~S}_{3}$ nanostructures from bismuth (III) thiourea and thiosemicarbazide complexes," Chemistry of Materials, vol. 21, pp. 1-10, 2009.

[28] F. Chen, Y. Cao, and D. Jia, "Facile synthesis of $\mathrm{Bi}_{2} \mathrm{~S}_{3}$ hierarchical nanostructure with enhanced photocatalytic activity," Journal of Colloid and Interface Science, vol. 404, pp. 110-116, 2013.

[29] E. Hu, X. Gao, A. Etogo, Y. Xie, Y. Zhong, and Y. Hu, "Controllable one-pot synthesis of various one-dimensional $\mathrm{Bi}_{2} \mathrm{~S}_{3}$ nanostructures and their enhanced visible-light-driven photocatalytic reduction of $\mathrm{Cr}(\mathrm{VI})$," Journal of Alloys and Compounds, vol. 611, pp. 335-340, 2014.

[30] K. Ai, Y. Liu, J. Liu, Q. Yuan, Y. He, and L. Lu, "Large-scale synthesis of Bi2S3Nanodots as a contrast agent for in vivo $\mathrm{X}$ - ray computed tomography imaging," Advanced Materials, vol. 23, no. 42, pp. 4886-4891, 2011.

[31] X. Luan, M. T. G. Wing, and Y. Wang, "Enhanced photocatalytic activity of graphene oxide/titania nanosheets composites for methylene blue degradation," Materials Science in Semiconductor Processing, vol. 30, pp. 592-598, 2015.

[32] D. Ayodhya and G. Veerabhadram, "Highly efficient sunlight-driven photocatalytic degradation of organic pollutants and fluorescence detection of $\mathrm{Hg}^{2+}$ using multifunctional GO- $\mathrm{Bi}_{2} \mathrm{~S}_{3}$ nanostructures," Journal of Photochemistry and Photobiology A: Chemistry, vol. 356, pp. 545-555, 2018.

[33] H. S. S. R. Matte, K. S. Subrahmanyam, and C. N. R. Rao, "Synthetic aspects and selected properties of graphene," Nanomaterials and Nanotechnology, vol. 1, pp. 5-13, 2011.

[34] P. Subramanyam, B. Meena, G. Neeraja Sinha, D. Suryakala, and C. Subrahmanyam, "Facile synthesis and photoelectrochemical performance of a $\mathrm{Bi}_{2} \mathrm{~S}_{3} @ \mathrm{rGO}$ nanocomposite photoanode for efficient water splitting," Energy and Fuels, vol. 35, no. 7, pp. 6315-6321, 2021.

[35] Y. Liu, M. Li, Y. Zheng et al., "Boosting potassium-storage performanceviathe functional design of a heterostructured $\mathrm{Bi}_{2} \mathrm{~S}_{3} @$ RGO composite," Nanoscale, vol. 12, no. 48, pp. $24394-$ 24402, 2020.

[36] R. Fahey and K. Hmd, "Degradation of some textile dyes using biological and physical treatments," B. Sc. Microbiol, pp. 2231, 2003.

[37] T. Desalegn, C. R. Ravikumar, and H. C. A. Murthy, "Ecofriendly synthesis of silver nanostructures using medicinal plant Vernonia amygdalina Del. leaf extract for multifunctional applications," Applied Nanoscience, vol. 11, no. 2, pp. 535-551, 2021.

[38] Y. X. Gan, A. H. Jayatissa, Z. Yu, X. Chen, and M. Li, "Hydrothermal synthesis of nanomaterials," Journal of Nanomaterials, vol. 2020, Article ID 8917013, 3 pages, 2020.

[39] B. Meka Chufa, B. Abdisa Gonfa, T. Yohannes Anshebo, and G. Adam Workneh, "A novel and simplest green synthesis method of reduced graphene oxide using methanol extracted Vernonia amygdalina: large-scale production," Advances in Condensed Matter Physics, vol. 2021, Article ID 6681710, 10 pages, 2021.

[40] D. G. Walker, W. H. R. Shaw, and D. G. Walker, "The decomposition of thiourea in water solutions," J. Am. Chem. soc., vol. 105, pp. 1954-1957, 1956.

[41] M. P. Deshpande, P. N. Sakariya, S. V. Bhatt, N. H. Patel, K. Patel, and S. H. Chaki, "Preparation and characterization of $\mathrm{Bi}_{2} \mathrm{~S}_{3}$ compound semiconductor," Bulletin of Materials Science, vol. 38, no. 1, pp. 83-88, 2015.

[42] Z. Ge, B. Zhang, Z. Yu, and J. F. Li, "Effect of spark plasma sintering temperature on thermoelectric properties of Bi2S3polycrystal," Journal of Materials Research, vol. 26, no. 21, pp. 2711-2718, 2011.

[43] D. C. Marcano, D. V. Kosynkin, J. M. Berlin et al., "Improved synthesis of graphene oxide," ACS Nano, vol. 4, no. 8, pp. 4806-4814, 2010.

[44] T. F. Emiru and D. W. Ayele, "Controlled synthesis, characterization and reduction of graphene oxide: a convenient method for large scale production," Egyptian Journal of Basic and Applied Sciences, vol. 4, no. 1, pp. 74-79, 2017.

[45] J. Hwang, J. Park, K. Yoon Chung, and J. Kim, "One-pot synthesis of Bi-reduced graphene oxide composite using 
supercritical acetone as anode for Na-ion batteries," Chemical Engineering Journal, vol. 387, p. 124111, 2020.

[46] Z. Zhang, C. Zhou, L. Huang et al., "Synthesis of bismuth sulfide/reduced graphene oxide composites and their electrochemical properties for lithium ion batteries," Electrochimica Acta, vol. 114, pp. 88-94, 2013.

[47] L. Zhang, N. Li, H. Jiu, and Q. Zhang, "Solvothermal synthesis of reduced graphene oxide-Bi2S3 nanorod composites with enhanced photocatalytic activity under visible light irradiation," Journal of Materials Science: Materials in Electronics, no. 3, 2015.

[48] Y. Liu, Y. Shi, X. Liu, and H. Li, "A facile solvothermal approach of novel $\mathrm{Bi}_{2} \mathrm{~S}_{3} / \mathrm{TiO}_{2} / \mathrm{RGO}$ composites with excellent visible light degradation activity for methylene blue," Applied Surface Science, vol. 2016, 2016.

[49] S. Shenoy, E. Jang, T. J. Park, C. S. Gopinath, and K. Sridharan, "Cadmium sulfide nanostructures: influence of morphology on the photocatalytic degradation of erioglaucine and hydrogen generation," Applied Surface Science, vol. 483, pp. 696705, 2019. 